\title{
Comparison of in-vitro stereoselective metabolism of bupropion in human, monkey, rat and mouse liver microsomes
}

Chandrali Bhattacharya, Danielle Kirby, Michael Van Stipdonk, Robert E. Stratford

\section{Introduction}

Bupropion has been marketed as Wellbutrin ${ }^{\circledR}$ and $\mathrm{Zyban}^{\circledR}$ for the management of depression and as a smoking cessation aid, respectively, since the early 1990s [1]. Its recent approval by the U.S. FDA in combination with naltrexone, Contrave ${ }^{\circledR}$, for obesity, and a recent positive outcome in clinical trials for attention-deficit/hyperactivity disorder (ADHD), further exemplify the multifaceted therapeutic potential of this drug [2-6]. However, despite being a biopharmaceutical classification system (BCS) class I drug, failure of generic bupropion to meet U.S. FDA bioequivalence standards has drawn attention to the problem of interpatient variability in its clinical response [7-15]. This is of concern due to its high propensity to induce seizures and other side effects [7, 10, 11, 16-19]. With over 40 million patients worldwide prescribed bupropion [1], understanding causes of inter-subject variability is critical. Variability regarding bupropion metabolism is considered chiefly responsible for variability in its response [10, 12-14, 20-22].

The disposition and pharmacology of bupropion are complex, since both bupropion and its metabolites have diverse pharmacokinetic and pharmacodynamic profiles [20-30]. Though bupropion is clinically administered as a racemate, plasma exposure of R-bupropion and its metabolites are reported to be higher than exposure to the S enantiomer and its metabolites [20-22]. Both enantiomers are reported to undergo stereoselective phase I and II metabolism mediated by multiple enzymes [20, 23, 28]. In-vitro and in-vivo studies indicate stereoselective phase I and II metabolic pathways contribute to observed differences in plasma profiles of bupropion enantiomers and their metabolites [20-23]. Furthermore, several

This is the author's manuscript of the article published in final edited form as:

Bhattacharya, C., Kirby, D., Van Stipdonk, M., \& Stratford, R. E. (2019). Comparison of In Vitro Stereoselective Metabolism of Bupropion in Human, Monkey, Rat, and Mouse Liver Microsomes. European Journal of Drug Metabolism and Pharmacokinetics, 44(2), 261-274. https://doi.org/10.1007/s13318-018-0516-4 
of the isoforms of these metabolizing enzymes and pharmacological targets are polymorphic $[31,32]$, making this also a potential factor contributing to inter-subject variability.

Despite lower plasma exposure of S,S-hydroxybupropion than R,R-hydroxybupropion and bupropion enantiomers, in-vitro [25, 26] and rodent behavioural studies [25, 26, 33, 34] indicate this metabolite plays an important role in the efficacy of the marketed product, both as an antidepressant and smoking cessation aid. Yet, attempts to bring S,S-hydroxybupropion or its structural analogs to the clinic have met with limited success [35, 36], implying that other metabolites may also contribute to bupropion`s overall therapeutic activity. This argument is strengthened by findings from studies that attribute pharmacological activity at several targets (dopamine and norepinephrine transporter inhibition, and agonist and/or antagonist effects at multiple central nicotinic receptors) to reductive metabolites [33, 37-39].

Previous studies of other centrally acting drugs have suggested that, despite lower brain cytochrome P450 (CYPs) expression than liver, local metabolism by CYPs may also influence exposure in brain, and that this might contribute to inter-individual variability in response [40-46]. The possibility of stereoselective brain disposition as a potential source of inter-subject variability in bupropion response is supported by rodent studies demonstrating nicotine-mediated induction of brain CYP2B [47]. Interestingly, metabolite-to-bupropion exposure ratios in plasma were different relative to those observed in rat brain [24] and human cerebrospinal fluid (CSF) [8], suggesting that plasma may not be an adequate indicator of brain exposure. One approach to understanding bupropion stereoselective disposition in the brain as a potential source of its inter-subject response variability would be to conduct plasma and brain pharmacokinetic studies in surrogate non-clinical species. Invitro and in-vivo studies conducted in mice, rats and monkeys have not comprehensively evaluated relative systemic exposure and, hence, potential pharmacologic contributions of individual R- or S-bupropion enantiomers and their metabolites [24, 25, 29, 48-51]. 
Thus, the aim of the present work was to compare the stereoselective phase I metabolism of bupropion in liver microsomes in three animal species with that in humans. Ideally, this would enable selection of the animal species most resembling bupropion stereoselective systemic metabolism in humans, and subsequently to be used for in-vivo experiments to measure bupropion enantiomer and corresponding metabolite diasteriomer exposure in brain interstitial fluid using microdialysis. This comprehensive exposure profile in brain interstitial fluid that bathes the multiple targets postulated to contribute to bupropion efficacy would ultimately support translational physiologic-based pharmacokinetic modeling and simulation to predict their contribution to target engagement in human brain, much like what has been done with atomoxetine and duloxetine [52, 53]. It is hoped these efforts will help predict the full gamut of bupropion and metabolite disposition in CNS, and so further our understanding of factors contributing to variability in bupropion's effectiveness in depression, weight loss and as adjunctive therapy in smoking cessation programs.

\section{Materials and methods}

\subsection{Materials}

R-bupropion, S-bupropion, R,R-hydroxybupropion, S,S-hydroxybupropion, racemic (rac)threohydrobupropion, rac-erythrohydrobupropion and acetaminophen were purchased from Toronto Research Chemicals (Toronto, Ontario, Canada). Nicotinamide adenine dinucleotide phosphate (NADPH) was purchased from Sigma Aldrich Chemical Co. (St. Louis, MO, U.S.A). Magnesium chloride heptahydrate, dibasic potassium phosphate anhydrous, monobasic potassium phosphate, HPLC grade methanol, and HPLC grade acetonitrile were purchased from Fisher Scientific (Fair Lawn, NJ, U.S.A). Pooled human liver microsomes, rat (adult male Sprague Dawley) liver microsomes and mouse (female CD-1) liver 
microsomes were purchased from Corning (Woburn, MA, U.S.A). Monkey (adult male marmoset) liver microsomes were purchased from BD Gentest (Woburn, MA, U.S.A).

\subsection{Liquid chromatography-tandem mass spectrometry (LC-MS/MS) method development and validation}

\subsubsection{Standard curve and quality control samples}

Individual standard stock solutions $(1 \mathrm{mg} / \mathrm{mL})$ each of R-bupropion, S-bupropion, S,Shydroxybupropion, R,R-hydroxybupropion, rac-threohydrobupropion, and racerythrohydrobupropion were prepared in $2 \mathrm{~mL}$ polypropylene tubes by dissolving the compounds in methanol which, as reported by Masters et al [54], have been demonstrated to be stable for 48 hours. All solutions were stored at $-20{ }^{\circ} \mathrm{C}$. On the day of an analysis, standards were prepared from the standard stock solutions. Standard curves for R-bupropion, R,R-hydroxybupropion, rac-threohydrobupropion, and rac-erythrohydrobupropion had the following concentrations: $0.025,0.05,0.20,1.0,5.0,20,100$, and $500 \mathrm{ng} / \mathrm{mL}$. S-bupropion, S,S-hydroxybupropion, rac-threohydrobupropion, and rac-erythrohydrobupropion had the following concentrations: $0.050,0.25,0.50,1.0,2.5,5.0$, and $10 \mathrm{ng} / \mathrm{mL}$. The smaller concentration range for S-bupropion and its metabolites was in response to observations from R-bupropion incubations in which metabolite concentrations did not exceed $10 \mathrm{ng} / \mathrm{mL}$. Quality control (QC) samples were run in triplicate along with standards to generate statistical data for assay accuracy and precision. QC samples had the following concentrations for R-bupropion, R,R-hydroxybupropion, rac-threohydrobupropion, and rac erythrohydrobupropion: $1 \mathrm{ng} / \mathrm{mL}$ (low QC), $100 \mathrm{ng} / \mathrm{mL}$ (medium QC), and $500 \mathrm{ng} / \mathrm{mL}$ (high QC). For S-bupropion and S,S-hydroxybupropion, QC samples had the following concentrations: $0.10 \mathrm{ng} / \mathrm{mL}$ (low QC), $1.0 \mathrm{ng} / \mathrm{mL}$ (medium QC), and $10 \mathrm{ng} / \mathrm{mL}$ (high QC). 
Samples were run in a matrix consisting of a 1:4 phosphate buffer ( $\mathrm{pH} 7.4)$ : acetonitrile mixture with the addition of $0.1 \%$ formic acid, containing $100 \mathrm{nM}$ acetaminophen (APAP) as the internal standard. In addition, standards and QC samples also contained $0.5 \mathrm{mg} / \mathrm{mL}$ of hepatic microsomes from the relevant species to be consistent with the incubated sample preparations.

\subsubsection{HPLC conditions}

Chromatography was performed using a Phenomenex KINTEX Luna ${ }^{\circledR}(150$ x $4.6 \mathrm{~mm}) 3.0$ micron $\mathrm{C} 18$ column. Achiral chromatography conditions were used; this was possible because separate incubations were conducted with the individual bupropion enantiomers. Injection volume was held constant at $3 \mu \mathrm{L}$, and the mobile phase was delivered as a gradient with a constant flow rate of $0.5 \mathrm{~mL} / \mathrm{min}$. A binary mobile phase was employed, which consisted of $\mathrm{A}$ ) aqueous solution of $20 \mathrm{mM}$ ammonium acetate plus $0.1 \%$ ammonium hydroxide ( $\mathrm{pH}$ 5.7) and B) methanol. The mobile phase was delivered as a gradient that began at $55 \% \mathrm{~A}$ and decreased to $45 \%$ of mobile phase A over 8 minutes. From $8-12$ minutes, mobile phase A was decreased to $35 \%$. From 12 to 14 minutes, mobile phase A was decreased from $35 \%$ to $25 \%$. Next, mobile phase A was decreased from $25 \%$ to $10 \%$ over 2 minutes, and was held for 2 minutes. From 18 minutes to 18.1 minutes mobile phase A was increased from $10 \%$ to $55 \%$ and held for 4.4 minutes to re-equilibrate the column for the next run.

\subsubsection{Triple-quadrupole mass spectrometer (QqQ/MS) conditions}

An Agilent 6460 with Agilent Jet Stream (AJS) Thermal Focusing Technology was used for the identification of analytes following LC separation. A multiple reaction monitoring (MRM) scanning method was used, because of its sensitivity. The optimal parameters for the 
AJS-ESI source were the following: gas temperature $\left(320^{\circ} \mathrm{C}\right)$; nebulizer pressure $(45 \mathrm{psi})$; sheath gas temperature $\left(400{ }^{\circ} \mathrm{C}\right)$; sheath gas flow $(11 \mathrm{~L} / \mathrm{min})$; capillary voltage $(4000 \mathrm{~V})$; and nozzle voltage $(500 \mathrm{~V})$. Bupropion and its metabolites were detected by positive ion electrospray ionization (ESI) using the mass transitions summarized in Table 1S (Online Resource 1). As shown in the table, mass transitions are identical for S-bupropion and its derived metabolites versus the respective stereoisomers of R-bupropion parent and its derived metabolites.

\subsubsection{Assay performance}

Calibration curves were analyzed by least squares regression analysis using Agilent MassHunter Workstation Quantitative Software ${ }^{\mathrm{TM}}$. The model used for each calibration curve was linear with a weighting of $1 / y$ for optimization for each analyte. Accuracy and precision for each analyte were determined based on the QC concentrations. Intra-assay precision and accuracy were calculated from three samples per QC concentration. Samples from each species were run on a single day, thus obviating the need for evaluation of inter-assay accuracy and precision. Accuracy is expressed as the percentage of the nominal concentration and precision is represented as percent coefficient of variation $(\% \mathrm{CV})$.

\subsection{Microsomal incubations}

Microsomal incubation mixtures consisted of $100 \mathrm{mM}$ potassium phosphate buffer $\mathrm{pH} 7.4,5$ $\mathrm{mM}$ magnesium chloride $\left(\mathrm{MgCl}_{2}\right), 0.5 \mathrm{mg} / \mathrm{mL}$ hepatic microsomes of a given species (human, monkey, rat, mouse), and substrate (R or S bupropion). Based on prior timedependent experiments of each species, 7-minutes was chosen as the incubation time. At this time and microsomal protein concentration, there was no observable substrate depletion; furthermore, formation of metabolites was linear with respect to time. Formation rate of 
the metabolite across the four species was determined at six different substrate concentrations ranging from 0.4 to $10 \mu \mathrm{M}$. This range is identical to that used by Sager et al [28] using human liver S9 fractions, and which encompasses clinically relevant bupropion concentrations [21]. It also encompasses the range of racemic bupropion and S,Shydroxybupropion concentrations observed in rats following a $10 \mathrm{mg} / \mathrm{kg}$ dose of racemic bupropion or $2 \mathrm{mg} / \mathrm{kg} \mathrm{S}, \mathrm{S}-h y d r o x y b u p r o p i o n$, which were maximal at $1 \mu \mathrm{M}$ and $3 \mu \mathrm{M}$, respectively [48]. Because similar systemic concentrations would be targeted for any of the three non-clinical species potentially used to evaluate in vivo plasma and brain pharmacokinetics of bupropion enantiomers and corresponding metabolites, the same concentration range used in the human incubations was also used for the non-clinical species. Reactions were initiated by adding NADPH (1 mM) following a 5-minute preincubation at $37^{\circ} \mathrm{C}$ in a water-bath. Total incubation volume after addition of NADPH was $100 \mu \mathrm{L}$. All concentrations stated above represent the final concentration in the $100 \mu \mathrm{L}$ incubation volume. The reaction was stopped with $400 \mu \mathrm{L}$ of ice-cold acetonitrile containing $0.1 \%$ (v/v) formic acid and acetaminophen (final internal standard concentration in $500 \mu \mathrm{L}$ was $0.1 \mu \mathrm{M}$ ). After stopping the reaction, all samples were centrifuged for 15 minutes at $3000 \mathrm{~g}, 4^{\circ} \mathrm{C}$ and the supernatant was transferred to microcentrifuge tubes and stored at $-80^{\circ} \mathrm{C}$ until analysis. Incubations were performed in triplicate and controls (no NADPH) were run in parallel. Microsomal protein binding was assumed to be negligible in all four species. In support of this assumption, Sager et al [28] demonstrated neglible binding of both bupropion enantiomers in human $\mathrm{S} 9$ fraction at $5 \mathrm{mg} / \mathrm{mL}$ protein. Data was analyzed using JMP ${ }^{\circledR}$, Version 13.2.0. SAS Institute Inc., Cary, NC and tested for statistical differences by one-way ANOVA with post-hoc Tukey`s test.

Since S- or R-4 hydroxybupropion are reported as minor metabolites in humans (contributing $<10 \%$ to overall bupropion clearance) [28], and with no reported 
pharmacological activity or commercially available standards, these metabolites were not evaluated. As shown in Fig. 1, a specific threohydrobupropion (S,S vs. R,R) or erythohydrobupropion ( $\mathrm{R}, \mathrm{S}$ vs $\mathrm{S}, \mathrm{R})$ metabolite is formed when incubations are conducted with a specific enantiomer. This obviated the need to correct standard concentrations of the racemic mixture of these two metabolite types (threo and erythro) for the individual diasteriomers when calculating unknown concentrations of these metabolites from the incubations.

Formation rate of a metabolite was plotted against substrate concentration and fit via linear or nonlinear regression models in $\mathrm{JMP}^{\circledR}$, Version 13.2.0. SAS Institute Inc., Cary, NC and GraphPad Prism version 6.00 for Windows (GraphPad Software, CA, USA). Final model selection was guided by precision of parameter estimates, objective function and examination of goodness-of-fit plots. When metabolite formation kinetics followed linear kinetics, intrinsic clearance $\left(\mathrm{CL}_{\mathrm{int}}\right)$ was calculated from the slope of formation rate $(\mathrm{v})$ versus substrate concentration (S) plots. When non-linear kinetics were observed, $\mathrm{CL}_{\text {int }}$ was calculated as the ratio of $V_{\max }$ and $\mathrm{K}_{\mathrm{m}}$ based on the Michaelis-Menten equation (1) that reduces to concentration-independent kinetics when $[\mathrm{S}]<<\mathrm{K}_{\mathrm{m}}$.

$$
\mathrm{v}=\frac{\mathrm{V}_{\max } \cdot[\mathrm{S}]}{\mathrm{K}_{\mathrm{m}}+[\mathrm{S}]}
$$

Intrinsic clearance $\left(\mathrm{CL}_{\mathrm{int}}\right)$ was scaled to intrinsic hepatic clearance $\left(\mathrm{CL}_{\mathrm{int}, \mathrm{H}}\right)$ using the equation below (2) for the four species. Values for the two ratios that are specific to each species are summarized in the respective table legends.

$$
\mathrm{CL}_{\mathrm{int}, \mathrm{H}}=\mathrm{CL}_{\mathrm{int}} \cdot \frac{\mathrm{mg} \text { microsomes }}{\text { gram }(\mathrm{g}) \text { of liver }} \cdot \frac{\text { liver weight }(\mathrm{g})}{\text { body weight }(\mathrm{kg})}
$$




\section{Results}

\subsection{LC-MS/MS method development and validation}

Chromatographic separation of bupropion (R or S), hydroxybupropion (S,S or R,R), racerythrohydrobupropion and rac-threohydrobupropion was successfully achieved using a Phenomenex KINTEX Luna ${ }^{\circledR}(150$ x 4.6 mm) 3.0-micron C18 column. Fig. 1S (Online Resource 3) shows a chromatogram for S-bupropion and its derived metabolites. As achiral conditions were used, the developed method was employed for both R- and S- bupropion and their corresponding metabolites, and was successfully reproducible for the four animal species. Bupropion enantiomer inversion was minimized by using a short incubation time of seven minutes, which is consistent with a reported half-life in plasma of 1.3 hours [28].

Assessment of method performance is summarized in Table 2S (Online Resource 2) Calibration curves generated were linear for all analytes where the common $\mathrm{r}^{2}$ values were $\geq$ 0.99. Assay accuracy and precision were $\leq 20 \%$ for all QC samples.

\subsection{Microsomal incubation kinetics}

Tables 1 - 4 summarize the kinetics of R- and S-bupropion phase I metabolism in human, marmoset, rat and mouse liver microsomes, respectively. Formation clearance $\left(\mathrm{CL}_{\mathrm{int}}\right)$ of each metabolite was estimated from the relationship between formation rate relative to the range of substrate concentrations evaluated $(0.4-10 \mu \mathrm{M})$. These relationships are summarized in Figs. $2-5$ for each species, respectively. In marmoset, a linear relationship was observed for all six metabolites; whereas, in the mouse, saturable kinetics were observed for all six metabolites. Human and rat formation kinetics were mixed linear and non-linear. Table 5 summarizes $\mathrm{V}_{\max }$ and $\mathrm{K}_{\mathrm{m}}$ estimates in cases where non-linear kinetics were observed. In such cases, $C L_{\text {int }}$ represents the ratio $V_{\max } / K_{m}$, which would apply to conditions in which substrate 
concentration $<<\mathrm{K}_{\mathrm{m}}$ according to Equation 1.

\subsubsection{Characterization of bupropion metabolism in human liver microsomes (HLMs)}

With respect to the two bupropion isomers, total $\mathrm{CL}_{\text {int }}$ of $\mathrm{S}$-bupropion was 5.6-fold higher than R-bupropion (Table 1). The various fractions of this total contributed by the measured metabolites are also summarized in Table 1. The various fractions of measured metabolites contributing to the total $\mathrm{CL}_{\mathrm{int}}$ of each of the bupropion enantiomers are also summarized in Table 1. R,R-hydroxybupropion was found to be the major metabolite of R-bupropion, while S,S-threohydrobupropion was the major metabolite of S-bupropion. All three metabolites derived from S-bupropion had higher $\mathrm{CL}_{\text {int }}$ of formation compared to their corresponding diastereoisomers derived from R-bupropion. Fig. 6 summarizes the fractional clearance $\left(f_{m}\right.$, racemic) that each metabolite contributes to the clearance of racemic bupropion. In human liver microsomes, S,S-threohydrobupropion was found to be the major metabolite, contributing $37 \%$ to total racemic bupropion clearance.

\subsubsection{Characterization of bupropion metabolism in marmoset monkey liver microsomes (MMLMs)}

In MMLMs, total CL $\mathrm{L}_{\text {int }}$ of S-bupropion was 1.3-fold relative to R-bupropion (Table 2). As with HLMs, R,R-hydroxybupropion was found to be the major metabolite of R-bupropion; however, unlike HLMs, in which S,S-threohydrobupropion was the major metabolite derived from S-bupropion, S,S-hydroxybupropion was the major metabolite in MMLMs. Formation clearance ( $\mathrm{CL}_{\text {int }}$ ) of S,S-hydroxybupropion and R,R-hydroxybupropion were similar in MMLMs. $\mathrm{CL}_{\text {int }}$ of the two-remaining metabolite diastereoisomer pairs was faster from Sbupropion; namely, S,S-threohydrobupropion was nearly 2-fold higher than R,Rthreohydrobupropion; R,S-erythrohydrobupropion was 3-fold higher than S,R- 
erythrohydrobupropion. For both enantiomers, the rank order for formation of the three metabolites was the same in this species. Considering the overall contribution of each of the measured metabolites to total racemic bupropion clearance (Fig. 6), R,R-hydroxybupropion was the major metabolite, contributing $36 \%$ to overall bupropion clearance $(0.71 / 2)$.

Comparing to HLMs, the rank order of R-bupropion-derived metabolite formation kinetics ( $f_{m}$, enantiomer) was the same in MMLMs. However, the rank order of S-bupropion-derived metabolite formation kinetics was different between the two species, with $\mathrm{f}_{\mathrm{m}}$, enantiomer of $\mathrm{S}, \mathrm{S}-$ hydroxybupropion being 3-fold higher, S,S-threohydrobupropion 3-fold lower and R,Serythrohydrobupropion 3.5-fold higher in MMLMs relative to HLMs.

\subsubsection{Characterization of bupropion metabolism in rat liver microsomes (RLMs)}

In striking contrast to HLMs and MMLMs, total CLint of S-bupropion in RLMs was 7-fold lower than R-bupropion (Table 3), and the erythrohydrobupropion isomers were the dominant metabolites formed for both R- and S-bupropion. While formation of R,Rhydroxybupropion, R,R-threohydrobupropion and S,S-hydroxybupropion followed linear kinetics, formation of S,R-erythrohydrobupropion, R,S-erythrohydrobupropion and S,Sthreohydrobupropion followed Michaelis-Menten kinetics (Fig. 4). Considering, the relative contribution of all the measured metabolites to racemic bupropion clearance, $\mathrm{S}, \mathrm{R}$ erythrohydrobupropion was the chief metabolite, contributing $44 \%$ to overall bupropion clearance (Fig. 6). In comparison to HLMs, $\mathrm{f}_{\mathrm{m}}$, enantiomer of R,R-hydroxybupropion in RLMs was 5-fold lower; R,R-threohydrobupropion was 31-fold lower and that of S,R erythrohydrobupropion was 7-fold higher in RLMs. The $\mathrm{f}_{\mathrm{m}}$, enantiomer of S,S-hydroxybupropion in RLMs was nearly the same as HLMs; S,S-threohydrobupropion was 2-fold lower and R,Serythrohydrobupropion was 7-fold higher in RLMs. 


\subsubsection{Characterization of bupropion metabolism in mouse liver microsomes (MLMs)}

In MLMs, total CLint of S-bupropion was nearly 2-fold lower than R-bupropion (Table 4). Like rats, and in contrast to humans, total R-bupropion $\mathrm{CL}_{\text {int }}$ was faster than S-bupropion. R,R-hydoxybupropion was responsible for $95 \%$ of total R-bupropion clearance; likewise, $\mathrm{S}, \mathrm{S}$-hydroxybupropion was the main metabolite from S-bupropion phase I metabolism $\left(\mathrm{f}_{\mathrm{m}}\right.$, enantiomer $=95 \%$ ). Of all the measured metabolites, both S,S- and R,R-hydroxybupropion were found to contribute $48 \%$ each towards racemic bupropion clearance (Fig. 6). Comparing the fraction that each metabolite contributes to $C L_{i n t, H}$ for an enantiomer ( $\left.f_{m \text {, enantiomer }}\right)$, it was observed that R,R-hydroxybupropion formation was 2-fold higher, R,R-threohydrobupropion was 8-fold lower and that of S,R -erythrohydrobupropion was 13-fold lower than HLMs. The

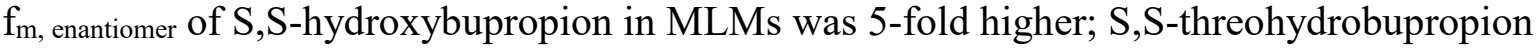
was 38-fold lower and R,S-erythrohydrobupropion was 2-fold lower than HLMs.

As summarized in Fig. 6, comparing across the four species, the total hydroxybupropion proportion contributing to racemic bupropion clearance was highest in the mouse (96\%), followed by monkey (62\%), human (38\%) and least in rat (17\%).

Threohydrobupropion was the most prevalent metabolite in human microsomes (53\%), followed by monkey $(23 \%)$, rat $(17 \%)$ and least in mouse $(3 \%)$. The highest fraction of total erythrohydrobupropion was observed in the rat (66\%), followed by monkey (14\%), human (9\%) and least in mouse liver microsomes (1.3\%).

\section{Discussion}

Despite proven efficacy, bupropion therapy is associated with wide inter-subject variability in elinieal respense $[11,18,21,55]$. Complex pharmacokineties and pharmacology of this drug, which includes formation of several active metabolites displaying variations in their own clearance to secondary metabolites, are the attributed causes $[20-22,25,28,30,33,50$, 
56]. In order to advance understanding of this variability and its sources, application of nonelinical animal experiments designed to enable chiral resolution of bupropion enantiomers and phase I metabolite diastereoisomers in plasma and brain might be useful. Preference in species selection would be based on similarity of metabolite formation kinetics relative to humans. The objective of the study reported herein was to compare phase I metabolite formation kinetics in rodents and NHPs to those in human in order to justify species selection for stereospecific CNS disposition studies. This is the essential stepping stone towards building a translational pharmacokinetic-pharmacodynamic model, to further our understanding of variability and its sources, associated with bupropion.

The 5.6-fold higher S-bupropion relative to R-bupropion total CLint in HLMs is close to the 5-fold difference observed in human liver S9 fractions [28]. This preferential loss of Sbupropion observed in two in vitro studies agrees with clinical results [21] identifying Sbupropion as the higher clearance enantiomer. The presently reported relative $\mathrm{CL}_{\text {int }}$ for $\mathrm{R}, \mathrm{R}-$ and S,S-hydroxybupropion in HLMs ( 0.48 versus $0.93 \mu \mathrm{l} / \mathrm{min} / \mathrm{mg}$ of microsomal protein, respectively) is in excellent agreement with the difference reported in human liver S9 fraction (0.47 versus $0.81 \mu \mathrm{l} / \mathrm{min} / \mathrm{mg}$ of S9 protein, respectively) [28]. This agreement confirms that hydroxybupropion formation is primarily by microsomal enzymes [23, 28, 30, 57]. For both diasteriomers, CYP2B6 was shown to be responsible for $90 \%$ of their formation, with minor contributions from CYP2C19 and CYP3A4 [28]. The linear formation rate observed for these two metabolites over the concentration range evaluated is also consistent with the estimated CYP2B6 $\mathrm{K}_{\mathrm{m}}$ values being $>100 \mu \mathrm{M}$ for R- and S-bupropion [28]. Disparity in CLint of R,R- and S,S-threohydrobupropion formation between HLMs (0.27 and 3.59 $\mu \mathrm{L} / \mathrm{min} / \mathrm{mg}$ protein, respectively) and the $\mathrm{S} 9$ fraction $(0.69$ and $5.61 \mu \mathrm{L} / \mathrm{min} / \mathrm{mg}$ protein, respectively) [28] is attributed to cytoplasmic aldo-keto reductase contribution in the S9 fraction [30, 57]. The $\mathrm{CL}_{\text {int }}$ of $\mathrm{S}, \mathrm{R}$ and R,S-erythrohydrobupropion $(0.11$ and $0.29 \mu 1 / \mathrm{min} / \mathrm{mg}$ 
of microsomal protein, respectively) observed in our study is in close agreement with reported values ( 0.11 and $0.25 \mu \mathrm{l} / \mathrm{min} / \mathrm{mg}$ of S9 protein, respectively) in liver S9 [28]. As with hydroxybupropion, this similarity supports that microsomal 11ß-HSD1 is primarily responsible for the production of erythrohydrobupropion diastereoisomers at clinically relevant bupropion concentrations[21]. It is also consistent with reports of minor contribution by cytosolic aldo-keto reductase in the formation of total erythrohydrobupropion [30, 57]. Overall, the finding that racemic bupropion clearance in HLMs is mainly by carbonyl reduction $(62 \%$ combined for threo- and erythro-hydrobupropion isomers, as summarized in Fig. 6) is consistent with published in-vitro and in-vivo results [13, 20, 21, 28, 30, 50, 57]. Studies conducted in rats and mice are unclear regarding the contribution of phase I metabolites to observed pharmacologic effects $[24-27,29,38,39,49,50,58]$. In part, this is due to different metabolic profiles between rats and mice. Our finding of higher hydroxybupropion formation in MLMs relative to RLMs is consistent with higher systemic exposure of this metabolite in-vivo in mice [24, 27, 49]. S,S-hydroxybupropion is an active metabolite, possessing potency comparable to bupropion at dopamine active transporter (DAT) and norepinephrine transporter (NET) and nicotinic receptors [25, 26, 33]. Combined, these pharmacokinetic and pharmacologic data are the basis for speculation for the superior translational efficacy of mice to humans [24-26, 29, 39, 49]. However, our findings summarized in Fig. 6 that threohydrobupropion diastereoisomers account for $<5 \%$ of racemic bupropion clearance in the MLMs versus 54\% in HLMs, and that threohydrobupropion possesses exposure-related pharmacologic or toxic activity [29, 33, 39], limits the translational value of the mouse from the standpoint of safety.

Based simply on the close genetic homology of NHPs to humans [59], it is reasonable to expect they would be a superior translational model to understand bupropion CNS disposition and ensuing central effects in humans. However, in vitro metabolite kinetics, and 
in vivo metabolite disposition in NHPs is limited [51, 60-62], and reports of stereoselective analysis are absent. We found that the total percentage of hydroxybupropion, threohydrobupropion, erythrohydrobupropion in marmoset monkey liver microsomes $(62 \%$, $23 \%, 14 \%$, respectively) is in good agreement with a previously published report $(62 \%, 28 \%, 10 \%)$ in baboon hepatic microsomes [60]. Of note, the Wang et al [60] study identified the CYP2B subfamily was responsible for hydroxybupropion formation, which is the case in humans, and supports similarity of bupropion metabolism between NHPs and humans. However, the Wang et al [60] study did not delineate the proportions of the diastereomer metabolites, which would be important to determine both systemically and centrally in order to more fully comprehend the complex CNS pharmacology of bupropion. Despite marked differences between bupropion metabolism in rodents and humans, in-vivo studies in rodents have identified an important contribution of phase I metabolites to bupropion effects [24, 26, 29, 33, 49]. Rodent studies also provide evidence that relative metabolite-to-bupropion exposure in brain is different than plasma [24]. Potential causes of the latter could be due to different permeability properties of metabolites relative to bupropion [48] and/or metabolism of bupropion in brain [63]. Overall, given the relative similarity of stereoselective bupropion phase I metabolism between MMLMs and HLMs we observed, in vivo systemic and brain disposition studies conducted in NHPs would be preferred over rodent studies to support development of translational physiologic-based pharmacokinetic models to improve our understanding of bupropion CNS pharmacology, including its potential to elicit seizures, in the context of its complex metabolic disposition.

A limitation of our analysis is that we did not measure blood-to-plasma concentration ratios of the two enantiomers in the four species, nor did we measure unbound plasma fractions $\left(f_{u}\right)$ of these enantiomers across species. These determinations would have enabled a determination of hepatic blood clearances of the two enantiomers in each species, which 
would have provided a more comprehensive comparison. However, Sager et al [28] who did estimate plasma binding and blood-plasma concentration ratios for the two enantiomers, indicated that differences in hepatic extraction alone were sufficient to explain bupropion stereoselective disposition. We invoke this argument on behalf of the other species [64]. As well, racemic bupropion $f_{u}$ in rats ranges from 0.31 to 0.49 [64] which is close to humans [28, 64] and therefore, considered similar.

\section{Conclusion}

This study used hepatic microsomes as a tool to compare the stereospecific formation kinetics of bupropion metabolites amongst three animal species to humans. To our knowledge, this is the first characterization of stereoselective metabolism of bupropion in rodent and NHP liver microsomes. Our findings demonstrate that phase I metabolism in NHPs best approximates that observed in humans, thereby supporting, based on similarity of stereoselective metabolite formation patterns alone, preferential use of this species to extend our understanding of stereoselective bupropion CNS disposition. For example, awareness of carrier-mediated transport at the BBB and/or metabolism within brain would generate new possibilities for causation of the unpredictable CNS adverse effects observed with this drug.

\section{Acknowledgement}

The authors thank Brandon Gufford (Indiana University), Jennifer Sager (Gilead Sciences), Andrea Masters (Indiana University) and Zeruesenay Desta (Indiana University) for their technical advice.

\section{Compliance with Ethical Standards}

The studies reported in this publication, were supported by a grant from the Charles Henry 
Leach II fund. All the authors report no declaration of interest.

\section{References}

1. Fava, M., et al., 15 Years of Clinical Experience With Bupropion HCl: From Bupropion to Bupropion SR to Bupropion XL. Primary Care Companion to The Journal of Clinical Psychiatry, 2005. 7(3): p. 106-113.

2. Ornellas, T. and B. Chavez, Naltrexone SR/Bupropion SR (Contrave): A New Approach to Weight Loss in Obese Adults. Pharmacy and Therapeutics, 2011. 36(5): p. 255262.

3. Reimherr, F.W., et al., Bupropion SR in adults with ADHD: a short-term, placebocontrolled trial. Neuropsychiatric Disease and Treatment, 2005. 1(3): p. 245-251.

4. Berigan, T.R., The Many Uses of Bupropion and Bupropion Sustained Release (SR) in Adults. Primary Care Companion to The Journal of Clinical Psychiatry, 2002. 4(1): p. 3032.

5. Hamedi, M., et al., Bupropion in adults with Attention-Deficit/Hyperactivity Disorder: a randomized, double-blind study. Acta Medica Iranica, 2014: p. 6.

6. Wilens, T.E., et al., An open trial of bupropion for the treatment of adults with attention-deficit/hyperactivity disorder and bipolar disorder. Biological Psychiatry. 54(1): p. 9-16.

7. Woodcock, J., M. Khan, and L.X. Yu Withdrawal of Generic Budeprion for Nonbioequivalence. New England Journal of Medicine, 2012. 367(26): p. 2463-2465.

8. Golden, R.N., et al., Bupropion in depression. II. The role of metabolites in clinical 
outcome. Arch Gen Psychiatry, 1988. 45(2): p. 145-9.

9. Connarn, J.N., et al., Identification of non-reported bupropion metabolites in human plasma. Biopharmaceutics \& Drug Disposition, 2016. 37(9): p. 550-560.

10. Hesse, L.M., et al., Pharmacogenetic determinants of interindividual variability in bupropion hydroxylation by cytochrome P450 2B6 in human liver microsomes. Pharmacogenetics and Genomics, 2004. 14(4): p. 225-238.

11. Laizure, S.C., et al., Pharmacokinetics of bupropion and its major basic metabolites in normal subjects after a single dose. Clinical Pharmacology \& Therapeutics, 1985. 38(5): p. 586-589.

12. Zhu, A.Z.X., et al., CYP2B6 and Bupropion's Smoking-Cessation Pharmacology: The Role of Hydroxybupropion. Clinical Pharmacology \& Therapeutics, 2012. 92(6): p. 771-777.

13. Benowitz, N.L., et al., Influence of CYP2B6 genetic variants on plasma and urine concentrations of bupropion and metabolites at steady state. Pharmacogenetics and genomics, 2013. 23(3): p. 135-141.

14. Zhu, A.Z.X., et al., Gene Variants in CYP2C19 Are Associated with Altered In Vivo Bupropion Pharmacokinetics but Not Bupropion-Assisted Smoking Cessation Outcomes. Drug Metabolism and Disposition, 2014. 42(11): p. 1971-1977.

15. Connarn, J.N., et al., Pharmacokinetics and Pharmacogenomics of Bupropion in Three Different Formulations with Different Release Kinetics in Healthy Human Volunteers. The AAPS Journal, 2017. 19(5): p. 1513-1522.

16. Grandas, F. and L. López-Manzanares, Bupropion-induced parkinsonism. Movement Disorders, 2007. 22(12): p. 1830-1831. 
17. Davidson, J., Seizures and bupropion: a review. Journal of Clinical Psychopharmacology, 1990. 10(1): p. 60-62.

18. Johnston JA, L.C., and Ascher JA. et al. , A 102-center prospective study of seizure in association with bupropion. J Clin Psychiatry, 1991 52: p. 450-456.

19. Beyens, M.-N., et al., Serious adverse reactions of bupropion for smoking cessation: analysis of the French Pharmacovigilance Database from 2001 to 2004. Drug Safety, 2008. 31(11): p. 1017-1026.

20. Gufford, B.T., et al., Stereoselective Glucuronidation of Bupropion Metabolites In Vitro and In Vivo. Drug Metabolism and Disposition, 2016. 44(4): p. 544-553.

21. Masters, A.R., et al., Chiral Plasma Pharmacokinetics and Urinary Excretion of Bupropion and Metabolites in Healthy Volunteers. Journal of Pharmacology and Experimental Therapeutics, 2016. 358(2): p. 230-238.

22. Kharasch, E.D., D. Mitchell, and R. Coles, Stereoselective Bupropion Hydroxylation as an In Vivo Phenotypic Probe for Cytochrome P4502B6 (CYP2B6) Activity. The Journal of Clinical Pharmacology, 2008. 48(4): p. 464-474.

23. Coles, R. and E.D. Kharasch, Stereoselective Metabolism of Bupropion by Cytochrome P4502B6 (CYP2B6) and Human Liver Microsomes. Pharmaceutical research, 2008. 25(6): p. 1405-1411.

24. Suckow, R.F., et al., Pharmacokinetics of bupropion and metabolites in plasma and brain of rats, mice, and guinea pigs. Drug Metabolism and Disposition, 1986. 14(6): p. 692697.

25. Damaj, M.I., et al., Enantioselective Effects of Hydroxy Metabolites of Bupropion on 
Behavior and on Function of Monoamine Transporters and Nicotinic Receptors. Molecular Pharmacology, 2004. 66(3): p. 675.

26. Damaj, M.I., et al., Effects of Hydroxymetabolites of Bupropion on Nicotine Dependence Behavior in Mice. The Journal of Pharmacology and Experimental Therapeutics, 2010. 334(3): p. 1087-1095.

27. Carroll, F.I., et al., Chapter Five - Bupropion and Bupropion Analogs as Treatments for CNS Disorders, in Advances in Pharmacology, P.D. Linda, Editor. 2014, Academic Press. p. $177-216$.

28. Sager, J.E., L.S.L. Price, and N. Isoherranen, Stereoselective Metabolism of Bupropion to OH-bupropion, Threohydrobupropion, Erythrohydrobupropion, and 4'-OHbupropion in vitro. Drug Metabolism and Disposition, 2016. 44(10): p. 1709-1719.

29. Silverstone, P.H., et al., Convulsive liability of bupropion hydrochloride metabolites in Swiss albino mice. Annals of General Psychiatry, 2008. 7: p. 19-19.

30. Skarydova, L., et al., Deeper Insight into the Reducing Biotransformation of Bupropion in the Human Liver. Drug Metabolism and Pharmacokinetics, 2014. 29(2): p. 177184.

31. Swan, G.E., et al., Dopamine receptor DRD2 genotype and smoking cessation outcome following treatment with bupropion SR. The Pharmacogenomics Journal, 2004. 5: p. 21.

32. Spraggs CF, P.S., Dow D, Douglas C, McCarthy L, Manasco PK, Stubbins M, Roses AD, Pharmacogenetics and obesity: common gene variants influence weight loss response of the norepinephrine/dopamine transporter inhibitor GW320659 in obese subjects. . 
Pharmacogenetics and Genomics, 2005. 15(12): p. 883-889.

33. Bondarev, M.L., et al., Behavioral and biochemical investigations of bupropion metabolites. European Journal of Pharmacology, 2003. 474(1): p. 85-93.

34. Grabus, S.D., F.I. Carroll, and M.I. Damaj, Bupropion and its Main Metabolite Reverse Nicotine Chronic Tolerance in the Mouse. Nicotine \& Tobacco Research, 2012. 14(11): p. 1356-1361.

35. Deveaugh-Geiss, J., et al., GW320659 for the Treatment of AttentionDeficit/Hyperactivity Disorder in Children. Journal of the American Academy of Child \& Adolescent Psychiatry, 2002. 41(8): p. 914-920.

36. Volkow, N.D., et al., The slow and long-lasting blockade of dopamine transporters in human brain induced by the new antidepressant drug radafaxine predict poor reinforcing effects. Biological Psychiatry, 2005. 57(6): p. 640-646.

37. Ascher, J.A., et al., Bupropion: A review of its mechanism of antidepressant activity. The Journal of Clinical Psychiatry, 1995. 56(9): p. 395-401.

38. Schroeder, D.H., Metabolism and kinetics of bupropion. J Clin Psychiatry. , May 1983. 44((5 Pt 2)): p. 79-81.

39. Martin, P., et al., Antidepressant Profile of Bupropion and three Metabolites in Mice. Pharmacopsychiatry, 1990. 23(04): p. 187-194.

40. Agarwal, V., et al., Drug Metabolism in Human Brain: High Levels of Cytochrome P4503A43 in Brain and Metabolism of Anti-Anxiety Drug Alprazolam to Its Active Metabolite. PLoS ONE, 2008. 3(6): p. e2337. 
41. Miksys, S. and R.F. Tyndale, The Unique Regulation of Brain Cytochrome P450 2 (CYP2) Family Enzymes by Drugs and Genetics. Drug Metabolism Reviews, 2004. 36(2): p. 313-333.

42. Ravindranath, V., R.P. Kommaddi, and H.V. Pai. Unique cytochromes P450 in human brain: implication in disease pathogenesis. in Parkinson's Disease and Related Disorders. 2006. Vienna: Springer Vienna.

43. Khokhar, J.Y. and R.F. Tyndale, Drug Metabolism within the Brain Changes Drug Response: Selective Manipulation of Brain CYP2B Alters Propofol Effects. Neuropsychopharmacology, 2011. 36(3): p. 692-700.

44. Ferguson, C.S. and R.F. Tyndale, Cytochromes P450 in the brain: Emerging evidence for biological significance. Trends in pharmacological sciences, 2011. 32(12): p. 708-714.

45. Sharon, M. and R.F. Tyndale, Brain Drug-Metabolizing Cytochrome P450 Enzymes are Active In Vivo, Demonstrated by Mechanism-Based Enzyme Inhibition. Neuropsychopharmacology : official publication of the American College of Neuropsychopharmacology, 2009. 34(3): p. 634-640.

46. Toselli, F., P.R. Dodd, and E.M.J. Gillam, Emerging roles for brain drugmetabolizing cytochrome P450 enzymes in neuropsychiatric conditions and responses to drugs. Drug Metabolism Reviews, 2016. 48(3): p. 379-404.

47. Khokhar, J.Y., S.L. Miksys, and R.F. Tyndale, Rat brain CYP2B induction by nicotine is persistent and does not involve nicotinic acetylcholine receptors. Brain Research, 2010. 1348: p. 1-9.

48. Cremers, T.I.F.H., et al., Development of a Rat Plasma and Brain Extracellular Fluid 
Pharmacokinetic Model for Bupropion and Hydroxybupropion Based on Microdialysis Sampling, and Application to Predict Human Brain Concentrations. Drug Metabolism and Disposition, 2016. 44(5): p. 624-633.

49. Welch, R.M., A.A. Lai, and D.H. Schroeder, Pharmacological significance of the species differences in bupropion metabolism. Xenobiotica, 1987. 17(3): p. 287-298.

50. Meyer, A., et al., Formation of Threohydrobupropion from Bupropion Is Dependent on 11ß-Hydroxysteroid Dehydrogenase 1. Drug Metabolism and Disposition, 2013. 41(9): p. $1671-1678$.

51. Hansard, M.J., et al., A major metabolite of bupropion reverses motor deficits in 1methyl-4-phenyl-1,2,3,6-tetrahydropyridine-treated common marmosets. Behavioural Pharmacology, 2011. 22(3): p. 269-274.

52. Kielbasa, W., J.C. Kalvass, and R. Stratford, Microdialysis Evaluation of Atomoxetine Brain Penetration and Central Nervous System Pharmacokinetics in Rats. Drug Metabolism and Disposition, 2009. 37(1): p. 137-142.

53. Kielbasa, W. and R.E. Stratford, Exploratory Translational Modeling Approach in Drug Development to Predict Human Brain Pharmacokinetics and Pharmacologically Relevant Clinical Doses. Drug Metabolism and Disposition, 2012. 40(5): p. 877-883.

54. Masters, A.R., et al., Stereoselective method to quantify bupropion and its three major metabolites, hydroxybupropion, erythro-dihydrobupropion, and threo-dihydrobupropion using HPLC-MS/MS. Journal of Chromatography B.

55. Dunner DL, Z.S., and Billow AA. et al., A prospective safety surveillance study for bupropion sustained-release in the treatment of depression. J Clin Psychiatry., 1998. 59: p. 
$366-373$.

56. Stahl, S.M., et al., A Review of the Neuropharmacology of Bupropion, a Dual Norepinephrine and Dopamine Reuptake Inhibitor. Primary Care Companion to The Journal of Clinical Psychiatry, 2004. 6(4): p. 159-166.

57. Connarn, J.N., et al., Metabolism of Bupropion by Carbonyl Reductases in Liver and Intestine. Drug Metabolism and Disposition, 2015. 43(7): p. 1019-1027.

58. Bruijnzeel, A.W. and A. Markou, Characterization of the effects of bupropion on the reinforcing properties of nicotine and food in rats. Synapse, 2003. 50(1): p. 20-28.

59. Dalgaard, L., Comparison of minipig, dog, monkey and human drug metabolism and disposition. Journal of Pharmacological and Toxicological Methods, 2015. 74: p. 80-92.

60. Wang, X., et al., Metabolism of bupropion by baboon hepatic and placental microsomes. Biochemical Pharmacology, 2011. 82(3): p. 295-303.

61. Schindler, C.W., et al., Comparison of the effects of methamphetamine, bupropion and methylphenidate on the self-administration of methamphetamine by rhesus monkeys. Experimental and Clinical Psychopharmacology, 2011. 19(1): p. 1-10.

62. Banks, M.L., D.A. Smith, and B.E. Blough, Methamphetamine-like discriminative stimulus effects of bupropion and its two hydroxy metabolites in male rhesus monkeys. Behavioural pharmacology, 2016. 27(2-3 Spec Iss): p. 196-203.

63. Miksys, S., et al., Smoking, alcoholism and genetic polymorphisms alter CYP2B6 levels in human brain. Neuropharmacology, 2003. 45(1): p. 122-132.

64. Avdeef, A., Permeability:Blood-Brain Barrier in Absorption and drug development 
solubility, permeability, and charge state. 2012, Hoboken, N.J. : John Wiley \& Sons:

Hoboken, N.J. p. 595. 


\section{Tables}

Table 1 Kinetics of R- and S-bupropion metabolism in human liver microsomes

\begin{tabular}{lccc}
\hline Substrate and metabolites & $\mathrm{CL}_{\text {int }}$ & $\mathrm{CL}_{\text {int, }{ }^{\mathrm{a}}}$ & $\mathrm{f}_{\mathrm{m}, \text { enantiomer }}$ \\
& $(\mu \mathrm{l} / \mathrm{min} / \mathrm{mg}$ of microsomal protein $)$ & $(\mathrm{L} / \mathrm{h})$ & \\
\hline
\end{tabular}

R-bupropion

$\begin{array}{lccc}\text { R,R-hydroxybupropion } & 0.48 & 2.12 & 0.56 \\ \text { R,R-threohydrobupropion } & 0.27 & 1.19 & 0.31 \\ \text { S,R-erythrohydrobupropion } & 0.11 & 0.49 & 0.13 \\ \text { Total R-bupropion CL }_{\text {int }} & 0.86 & 3.80 & \end{array}$

S-bupropion

$\begin{array}{lccc}\text { S,S-hydroxybupropion } & 0.93 & 4.14 & 0.19 \\ \text { S,S-threohydrobupropion } & 3.59 & 16.01 & 0.75 \\ \text { R,S-erythrohydrobupropion } & 0.29 & 1.29 & 0.06 \\ \text { Total S-bupropion CL } & & & \end{array}$

${ }^{a}$ Microsomal intrinsic clearance $\left(\mathrm{CL}_{\text {int }}\right)$ values were scaled to hepatic intrinsic clearance $\left(\mathrm{CL}_{\text {int, }} \mathrm{H}\right)$ using the scaling factor of $40 \mathrm{mg}$ microsomal protein/g liver. Assuming a body weight of $81 \mathrm{~kg}$ and $22 \mathrm{~g}$ liver $/ \mathrm{kg}$ body weight results in $1782 \mathrm{~g}$ liver weight. These values are from SIMCYP ${ }^{\circledR}$ simulator, version 17 , Certara ${ }^{\circledR}$.

${ }^{\mathrm{b}}$ Fractional contribution of a metabolite to the total bupropion enantiomer $\mathrm{CL}_{\text {int, }}$ ( $\left(\mathrm{f}_{\mathrm{m}}\right.$, enantiomer). 
Table 2 Kinetics of R- and S-bupropion metabolism in monkey liver microsomes

\begin{tabular}{lcc}
\hline Substrate and metabolites & $\mathrm{CL}_{\text {int }}$ & $\mathrm{CL}_{\text {int, }{ }^{\mathrm{a}}} \mathrm{f}_{\mathrm{m}, \text { enantiomer }}{ }^{\mathrm{b}}$ \\
& $(\mu \mathrm{l} / \mathrm{min} / \mathrm{mg}$ of microsomal protein $)$ & $(\mathrm{L} / \mathrm{h})$ \\
\hline
\end{tabular}

R-bupropion
R,R-hydroxybupropion
1.02
0.16
0.71
R,R-threohydrobupropion
0.29
0.04
0.20
S,R-erythrohydrobupropion
0.12
0.02
0.08
Total R-bupropion $\mathrm{CL}_{\text {int }}$
0.22

S-bupropion

S,S-hydroxybupropion

0.97

0.15

0.52

S,S-threohydrobupropion

0.50

0.08

0.27

R,S-erythrohydrobupropion

0.39

0.06

0.21

Total S-bupropion $\mathrm{CL}_{\text {int }}$

1.86

0.29

${ }^{a}$ Microsomal intrinsic clearance values were scaled to $\mathrm{CL}_{\mathrm{int}, \mathrm{H}} \mathrm{using}$ the scaling factor of $31 \mathrm{mg}$ microsomal protein/g liver. Assuming a body weight of $4 \mathrm{~kg}$ and $19.67 \mathrm{~g}$ liver/kg body weight results in $78.7 \mathrm{~g}$ liver weight. These values are from $\operatorname{SIMCYP}^{\circledR}$ simulator, version 17, Certara ${ }^{\circledR}$.

${ }^{b}$ Fractional contribution of a metabolite to the total bupropion enantiomer $C L_{\text {int, }}$ ( $\left(f_{m}\right.$, enantiomer $)$. 
Table 3 Kinetics of R-and S-bupropion metabolism in rat liver microsomes

\begin{tabular}{lcc}
\hline Substrate and metabolites & $\mathrm{CL}_{\text {int }}$ & $\mathrm{CL}_{\text {int, } \mathrm{H}}^{\mathrm{a}}$ \\
& $(\mu \mathrm{l} / \mathrm{min} / \mathrm{mg}$ of microsomal protein $)$ & $\mathrm{f}_{\mathrm{m}, \text { enantiomer }}$ \\
& $(\mathrm{L} / \mathrm{h})$ & \\
\hline
\end{tabular}

R-bupropion
R,R-hydroxybupropion
0.034
0.12
R,R-threohydrobupropion
0.10
0.003
0.01
S,R-erythrohydrobupropion
10.00
0.256
0.88
Total R-bupropion $\mathrm{CL}_{\text {int }}$
0.29

S-bupropion

S,S-hydroxybupropion

0.30

0.008

S,S-threohydrobupropion

0.46

0.012

0.34

R,S-erythrohydrobupropion

0.60

0.015

0.44

Total S-bupropion $\mathrm{CL}_{\text {int }}$

1.36

0.04

\footnotetext{
${ }^{\text {a }}$ Microsomal intrinsic clearance values were scaled to $C L_{\text {int, H }}$ using the scaling factor of $46 \mathrm{mg}$ microsomal protein/g liver. Assuming a body weight of $0.25 \mathrm{~kg}$ and $35.6 \mathrm{~g}$ liver $/ \mathrm{kg}$ body weight results in $8.9 \mathrm{~g}$ liver weight. These values are from SIMCYP $^{\circledR}$ simulator, version 17, Certara $^{\circledR}$.

${ }^{b}$ Fractional contribution of a metabolite to the total bupropion enantiomer $\mathrm{CL}_{\mathrm{int}, \mathrm{H}}\left(\mathrm{f}_{\mathrm{m}}\right.$, enantiomer $)$.
} 
Table 4 Kinetics of R- and S-bupropion metabolism in mouse liver microsomes

\begin{tabular}{lcc}
\hline Substrate and metabolites & $\mathrm{CL}_{\text {int }}$ & $\mathrm{CL}_{\text {int, } \mathrm{H}^{\mathrm{a}}} \mathrm{f}_{\mathrm{m}, \text { enantiomer }}{ }^{\mathrm{b}}$ \\
& $(\mu \mathrm{l} / \mathrm{min} / \mathrm{mg}$ of microsomal protein $)$ & $(\mathrm{L} / \mathrm{h})$ \\
\hline
\end{tabular}

R-bupropion

$\begin{array}{lccc}\text { R,R-hydroxybupropion } & 39.63 & 0.15 & 0.95 \\ \text { R,R-threohydrobupropion } & 1.73 & 0.007 & 0.04 \\ \text { S,R-erythrohydrobupropion } & 0.22 & 0.001 & 0.01 \\ {\text { Total R-bupropion } \mathrm{CL}_{\text {int }}}^{\text {n }} & 41.58 & 0.158 & \end{array}$

S-bupropion

S,S-hydroxybupropion

18.30

$0.071 \quad 0.95$

S,S-threohydrobupropion

0.43

$0.002 \quad 0.02$

R,S-erythrohydrobupropion

0.52

0.002

0.03

Total S-bupropion $\mathrm{CL}_{\text {int }}$

19.25

0.074

\footnotetext{
${ }^{\text {a }}$ Microsomal intrinsic clearance values were scaled to $C L_{\text {int, H }}$ using the scaling factor of $48 \mathrm{mg}$ microsomal protein $/ \mathrm{g}$ liver. Assuming a body weight of $0.025 \mathrm{~kg}$ and $51.2 \mathrm{~g}$ liver $/ \mathrm{kg}$ body weight results in $1.2 \mathrm{~g}$ liver weight. These values are from SIMCYP $^{\circledR}$ simulator, version 17, Certara $^{\circledR}$.

${ }^{b}$ Fractional contribution of a metabolite to the total bupropion enantiomer $\mathrm{CL}_{\mathrm{int}, \mathrm{H}}\left(\mathrm{f}_{\mathrm{m}}\right.$, enantiomer $)$.
} 
Table 5 Michaelis-Menten parameters for metabolites displaying saturable formation kinetics in liver microsomes

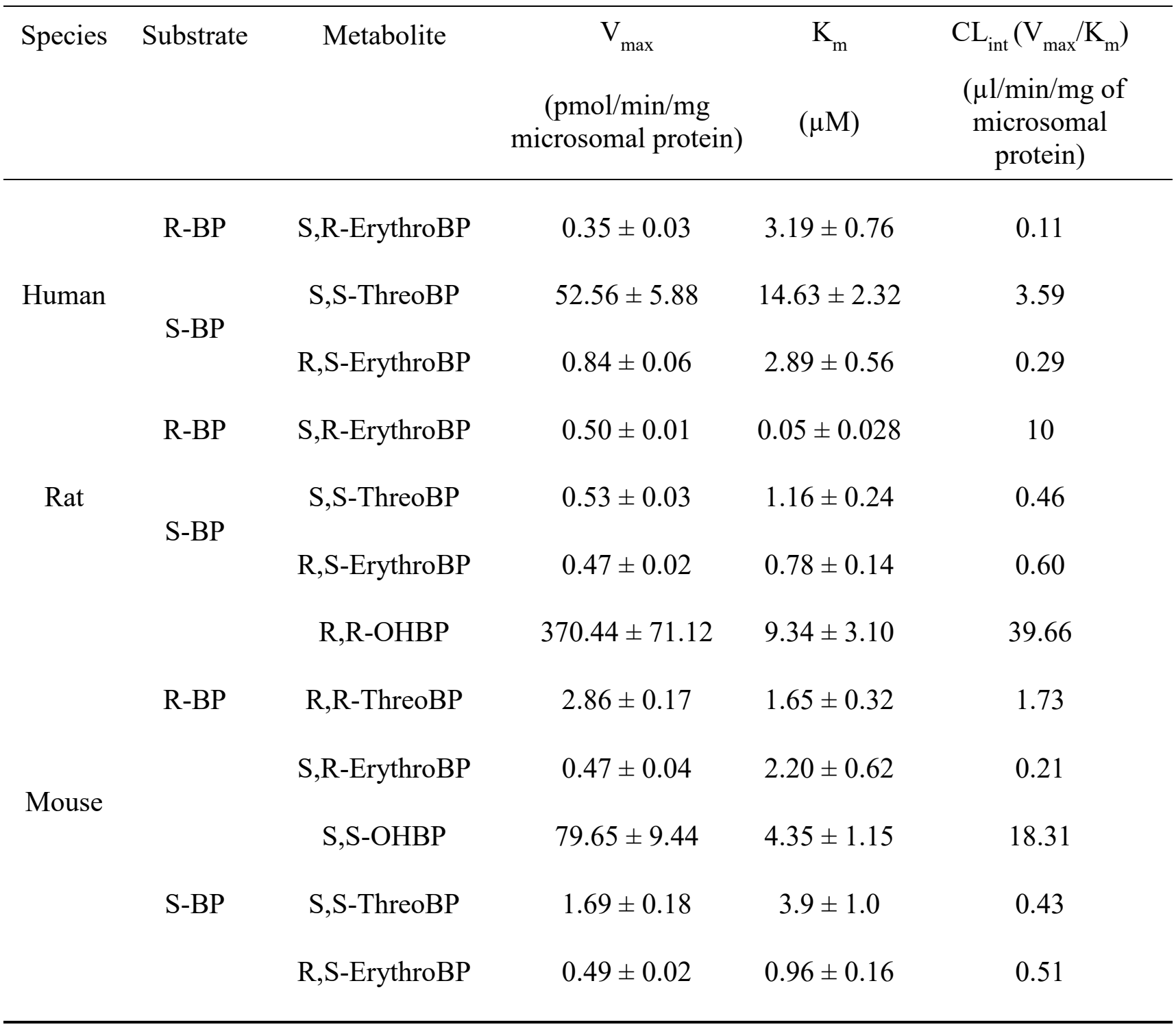

Values expressed represent mean \pm standard error of the estimate

BP : Bupropion, R,R-OHBP : R,R-hydroxybupropion, R,R-ThreoBP : R,R-threohydrobupropion,

S,R-ErythroBP : S,R-Erythrohydrobupropion. S,S-OHBP : S,S-hydroxybupropion, S,S-ThreoBP :

S,S-threohydrobupropion, R,S-ErythroBP : R,S-erythrohydrobupropion. 


\section{Figure Legends}

Fig. 1 Human liver microsomal metabolic pathways of bupropion stereoisomers. In addition to the shown metabolic pathways and responsible enzymes, all metabolites undergo glucuronidation. 11 $\beta$-HSD1: 11 $\beta$-Hydroxysteroid dehydrogenase 1. Adapted from Sager, Price, and Isoherranen 2016

Fig. 2 Metabolite formation kinetics of R-and S-bupropion in human liver microsomes. (a) Concentration dependent formation of R,R-hydroxybupropion, S,R-erythrohydrobupropion, R,R-threohydrobupropion from R-bupropion. (b) Concentration dependent formation of S,Shydroxybupropion, R,S-erythrohydrobupropion, S,S-threohydrobupropion from S-bupropion. Data are represented as the mean \pm S.D $(n=3)$

Fig. 3 Metabolite formation kinetics of R- and S-bupropion in monkey liver microsomes. (a) Concentration dependent formation of R,R-hydroxybupropion, S,R-erythrohydrobupropion, R,R-threohydrobupropion from R-bupropion. (b) Concentration dependent formation of S,Shydroxybupropion, R,S-erythrohydrobupropion, S,S-threohydrobupropion from S-bupropion. Data are represented as the mean \pm S.D $(n=3)$

Fig. 4 Metabolite formation kinetics of R- and S-bupropion in rat liver microsomes. (a) Concentration dependent formation of R,R-hydroxybupropion, S,R-erythrohydrobupropion, R,R-threohydrobupropion from R-bupropion. (b) Concentration dependent formation of S,Shydroxybupropion, R,S-erythrohydrobupropion, S,S-threohydrobupropion from S-bupropion. Data are represented as the mean \pm S.D $(n=3)$

Fig. 5 Metabolite formation kinetics of R- and S-bupropion in mouse liver microsomes. (a) Concentration dependent formation of R,R-hydroxybupropion, S,R-erythrohydrobupropion, R, R-threohydrobupropion from R-bupropion. (b) Concentration dependent formation of S,S- 
hydroxybupropion, R,S-erythrohydrobupropion, S,S-threohydrobupropion from S-bupropion. Data are represented as the mean \pm S.D $(n=3)$

Fig. 6 Interspecies comparison of the fraction of racemic bupropion metabolized to a specific

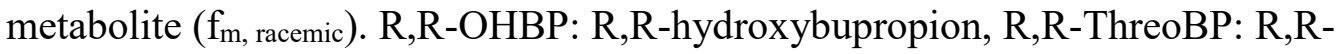
threohydrobupropion, S,R-ErythroBP: S,R-Erythrohydrobupropion. S,S-OHBP: S,Shydroxybupropion, S,S-ThreoBP: S,S-threohydrobupropion, R,S-ErythroBP: R,Serythrohydrobupropion 

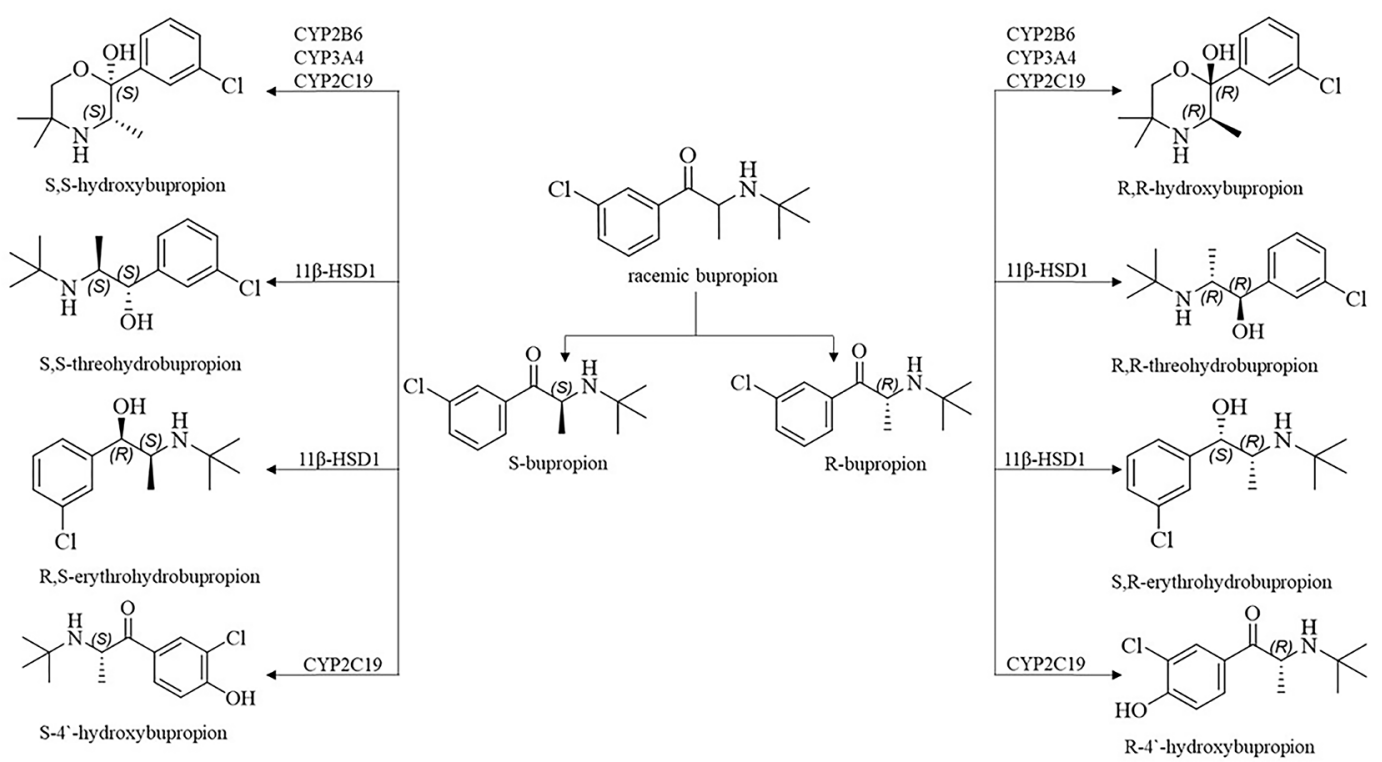

Figure 1 

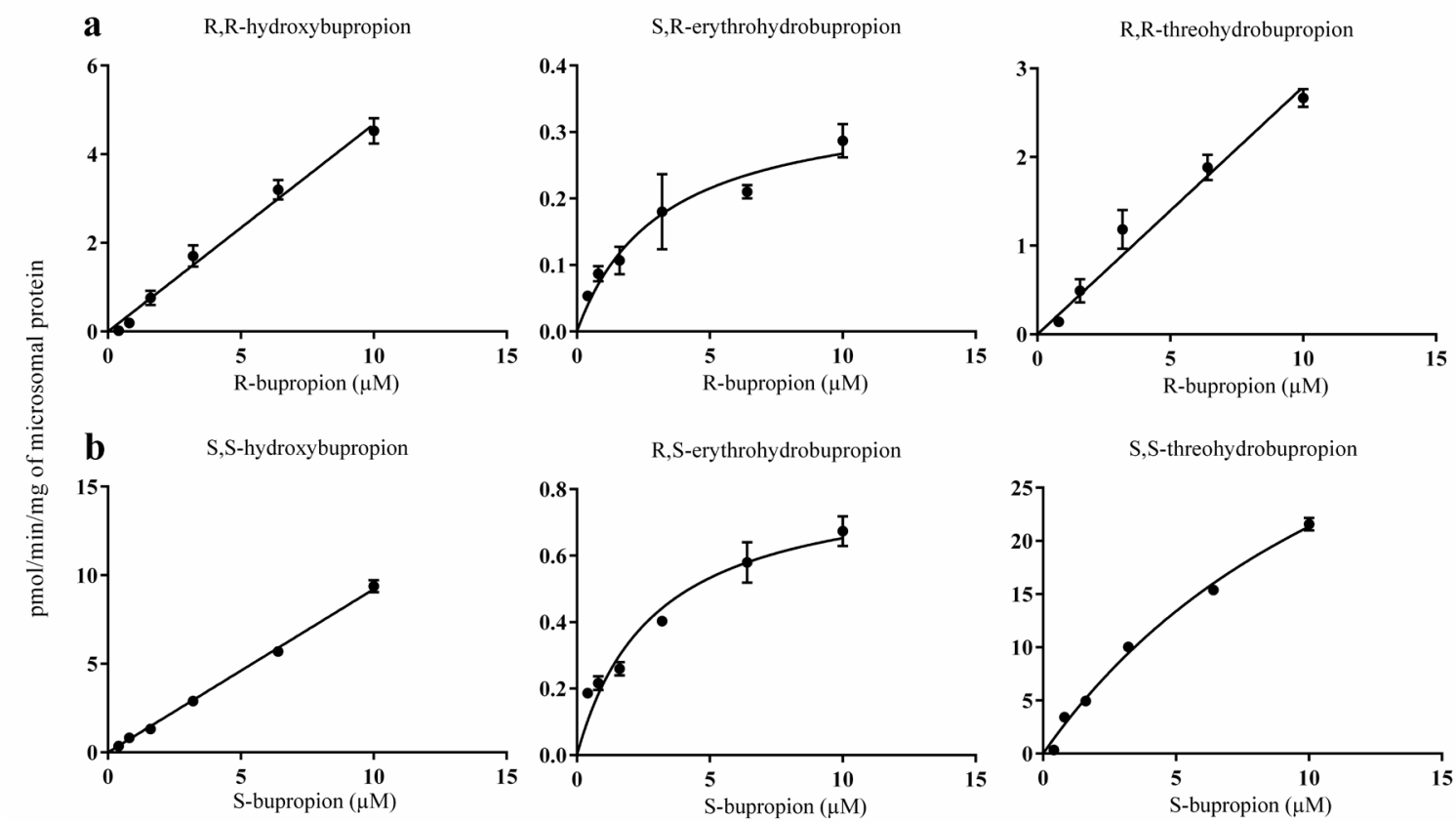

Figure 2
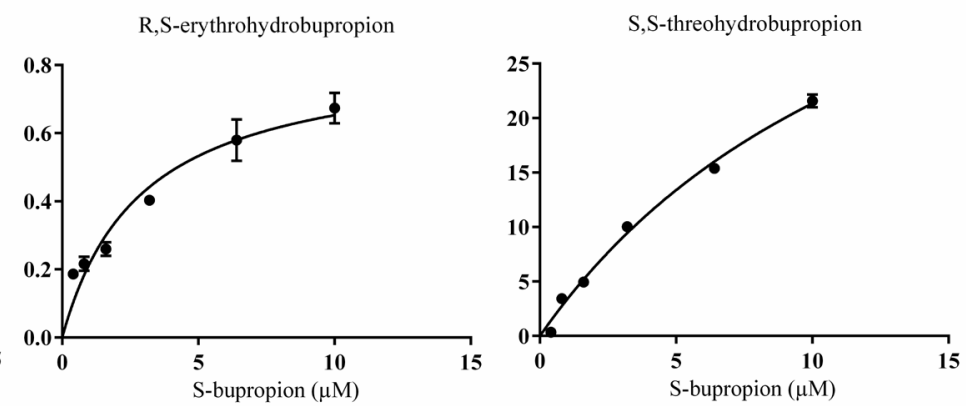

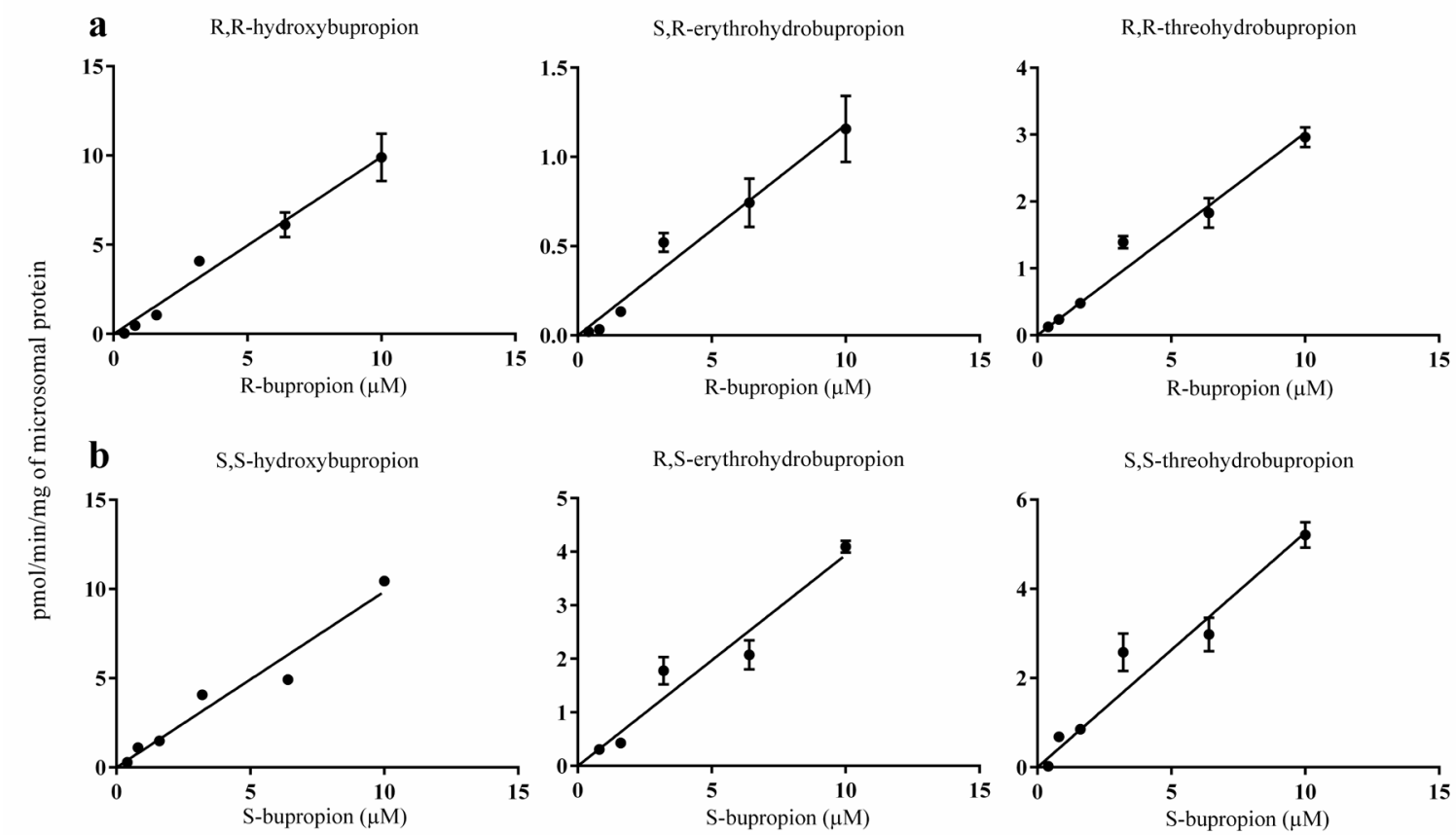

Figure 3
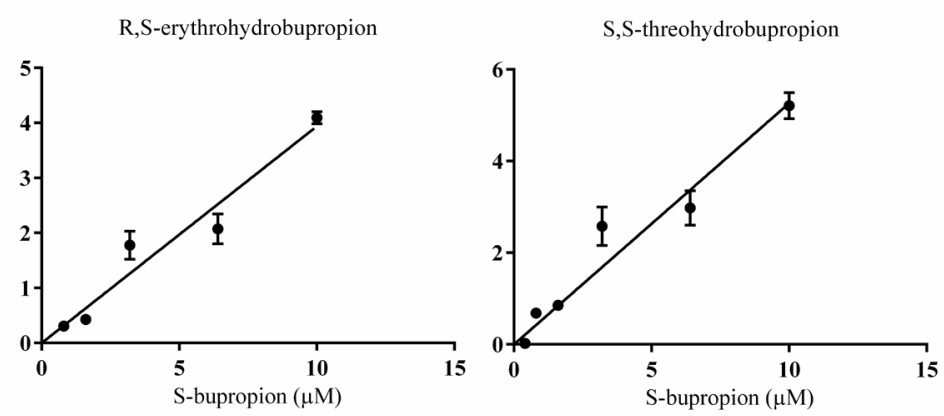

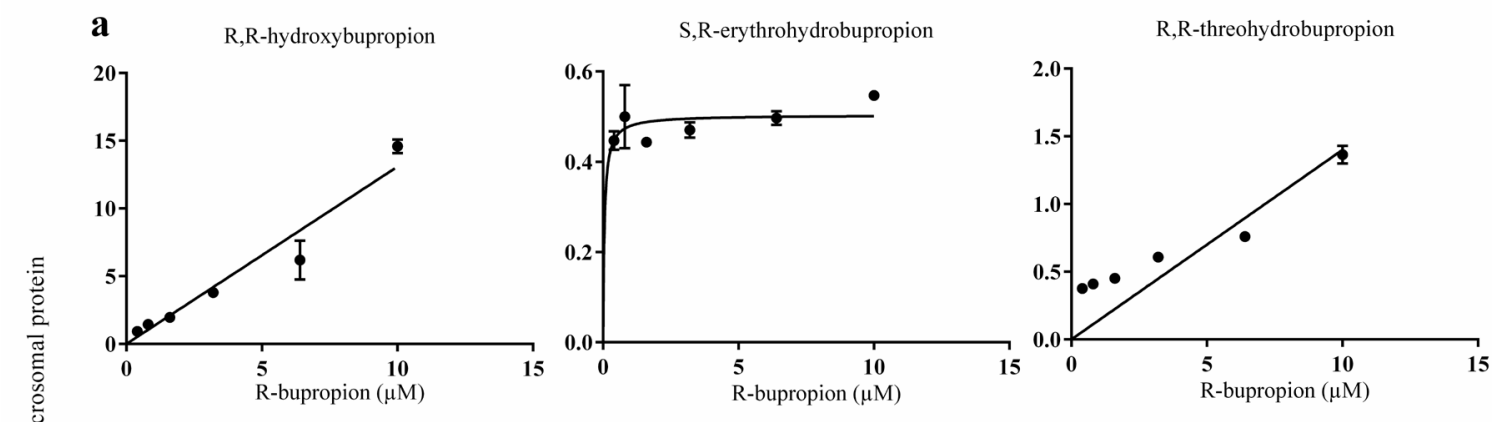

b S,S-hydroxybupropion

R,S-erythrohydrobupropion

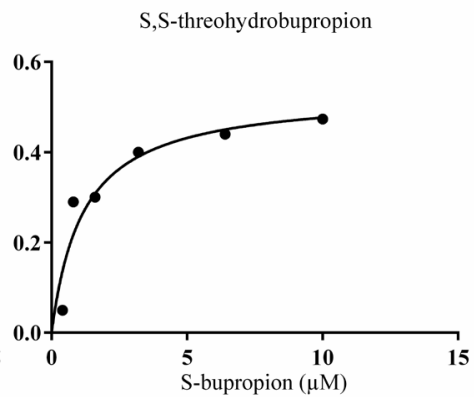

Figure 4 

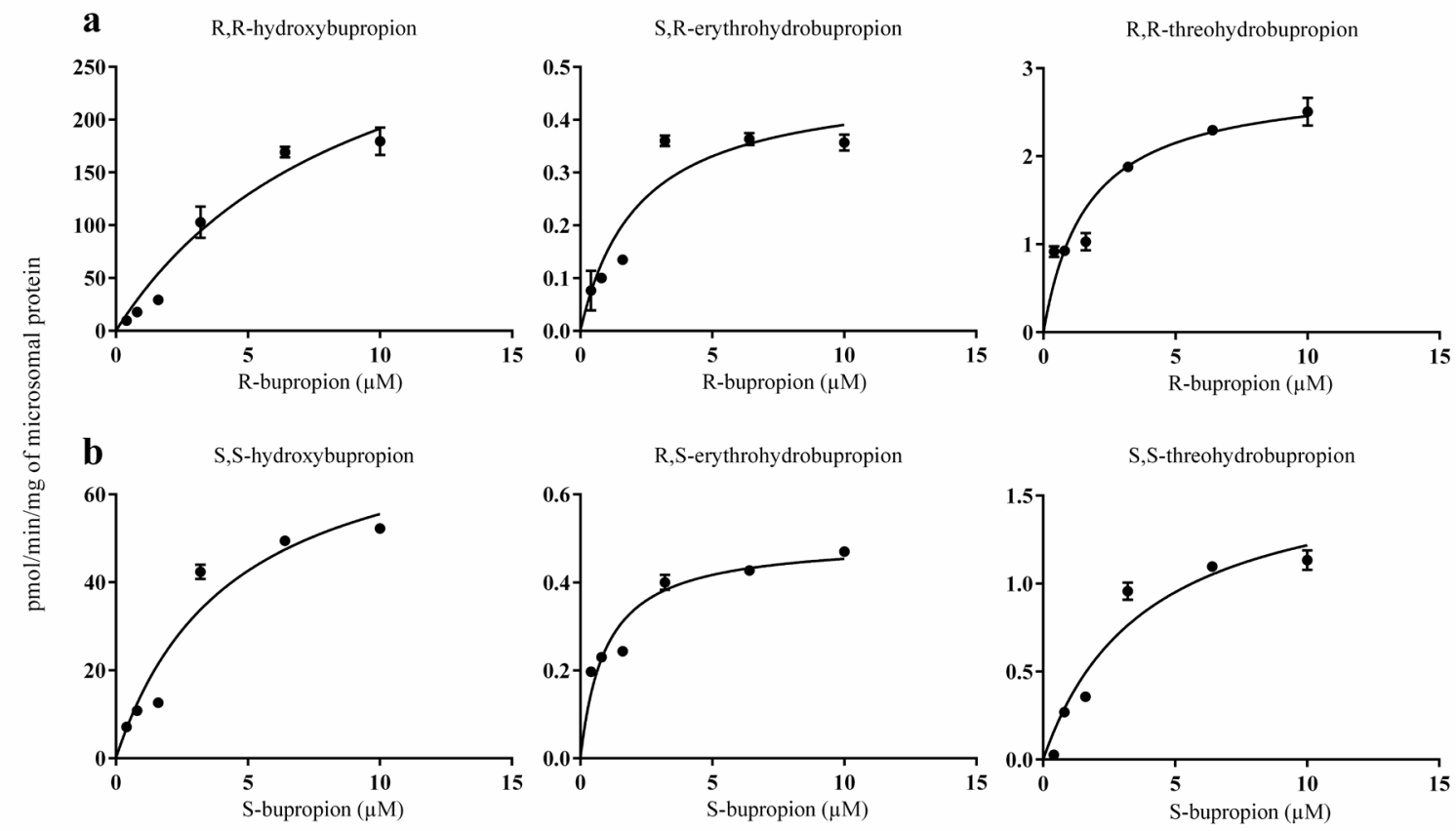

Figure 5
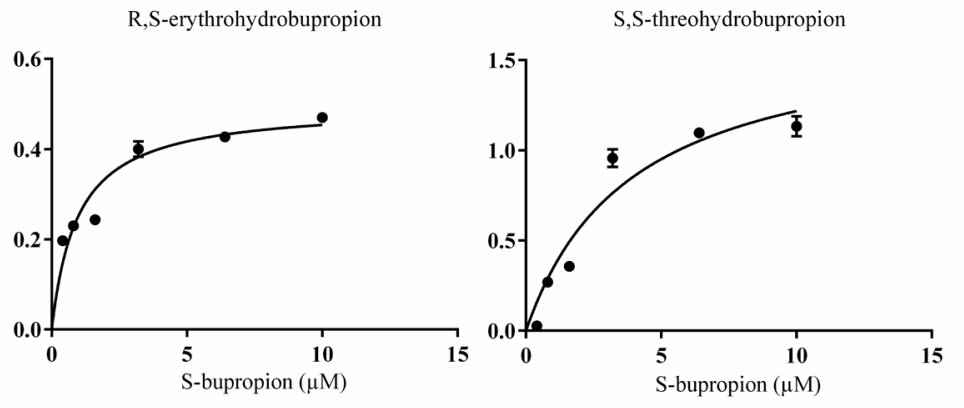


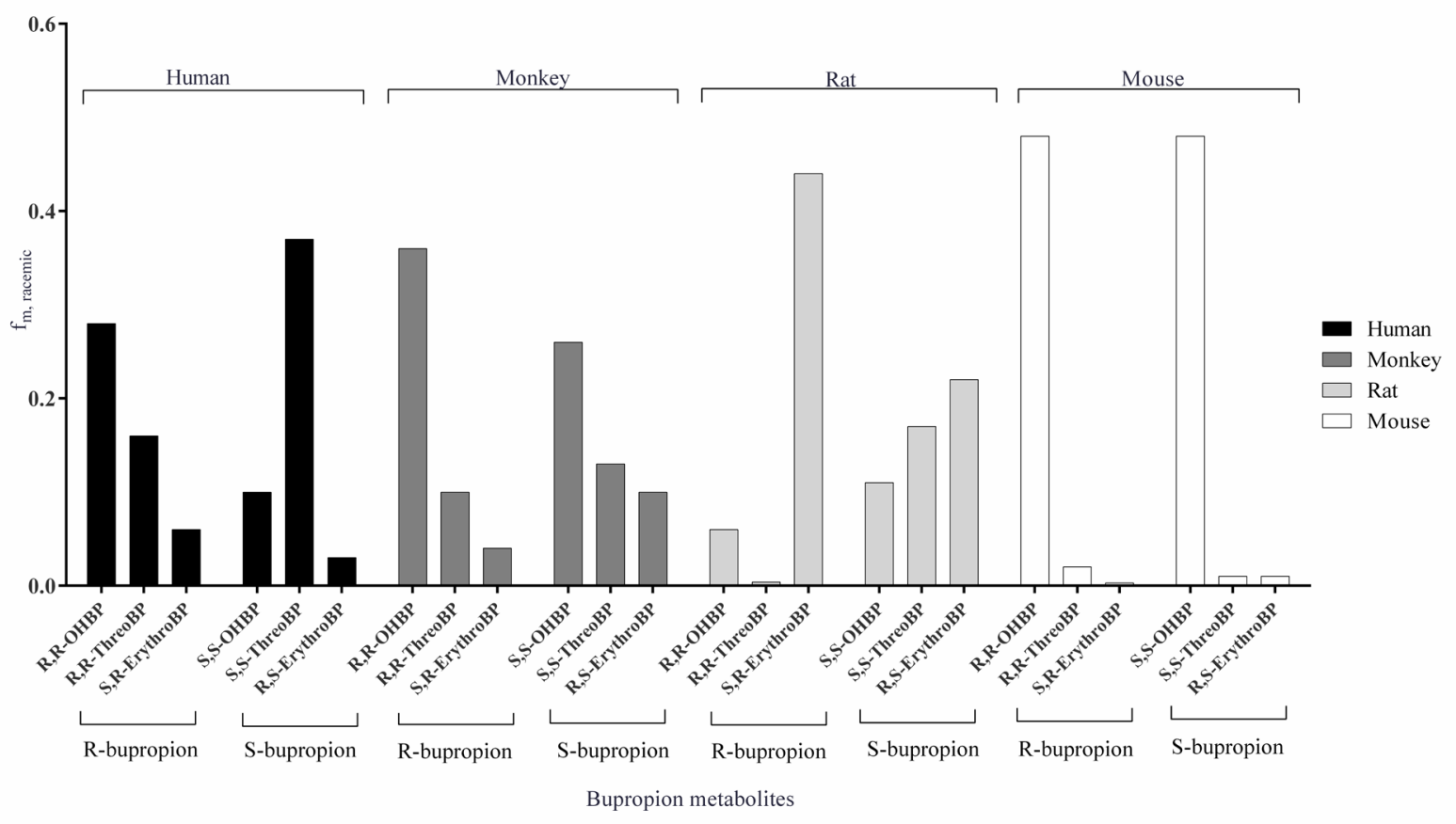

Figure 6 
Supporting Data

Article title : Comparison of in-vitro stereoselective metabolism of bupropion in human, monkey, rat and mouse liver microsomes

\section{European Journal of Drug Metabolism and Pharmacokinetics}

Author names: Chandrali Bhattacharya ${ }^{1}$, Danielle Kirby ${ }^{2}$, Michael Van Stipdonk ${ }^{2}$, and Robert E. Stratford ${ }^{1}$

Author affiliation: ${ }^{1}$ Graduate School of Pharmaceutical Sciences, Duquesne University, 600 Forbes Avenue, Pittsburgh, PA 15282 U.S.A ; ${ }^{2}$ Department of Chemistry and Biochemistry, Duquesne University, 600 Forbes Avenue Pittsburgh, PA 15282 U.S.A

Corresponding author email: robstrat@iu.edu

\section{Online Resource 1}

Table 1S MS/MS settings for R- and S-bupropion, their metabolites and acetaminophen.

\begin{tabular}{lcccccc}
\hline \multicolumn{1}{c}{ Analyte } & $\begin{array}{c}\text { Q1 } \\
(\mathrm{m} / \mathrm{z})\end{array}$ & $\begin{array}{c}\text { Q3 } \\
(\mathrm{m} / \mathrm{z})\end{array}$ & $\begin{array}{c}\text { Collision } \\
\text { Energy } \\
(\mathrm{eV})\end{array}$ & $\begin{array}{c}\text { Cell } \\
\text { Accelerator } \\
(\mathrm{V})\end{array}$ & $\begin{array}{c}\text { Fragmentor } \\
(\mathrm{V})\end{array}$ & Polarity \\
\hline S-bupropion & 240 & 184 & 5 & 8 & 60 & + \\
S,S-hydroxybupropion & 256 & 238 & 5 & 8 & 60 & + \\
R,S-erythrohydrobupropion & 242 & 168 & 10 & 8 & 75 & + \\
S,S-threohydrobupropion & 242 & 168 & 10 & 8 & 75 & + \\
R-bupropion & 240 & 184 & 5 & 8 & 60 & + \\
R,R-hydroxybupropion & 256 & 238 & 5 & 8 & 60 & + \\
S,R-erythrohydrobupropion & 242 & 168 & 10 & 8 & 75 & + \\
R,R-threohydrobupropion & 242 & 168 & 10 & 8 & 75 & + \\
Acetaminophen (APAP) & 152 & 110 & 21 & 4 & 75 & + \\
\hline
\end{tabular}


Article Title : Comparison of in-vitro stereoselective metabolism of bupropion in human, monkey, rat and mouse liver microsomes European Journal of Drug Metabolism and Pharmacokinetics

Author names: Chandrali Bhattacharya ${ }^{1}$, Danielle Kirby ${ }^{2}$, Michael Van Stipdonk ${ }^{2}$, and Robert E. Stratford ${ }^{1}$

${ }^{1}$ Graduate School of Pharmaceutical Sciences, Duquesne University, 600 Forbes Avenue, Pittsburgh, PA 15282 ; ${ }^{2}$ Department of Chemistry and Biochemistry, Duquesne University, 600 Forbes Avenue Pittsburgh, PA 15282 U.S.A Corresponding author email: robstrat@in.edu

Online Resource 2

Table 2S Intra-assay precision and accuracy for the quantitative analysis of bupropion and its metabolites in liver microsomes from the four animal species. Data are expressed as Mean \pm SD $(n=3)$.

\begin{tabular}{|c|c|c|c|c|c|c|c|c|c|c|c|c|c|c|c|c|c|}
\hline \multirow[b]{3}{*}{ Analytes } & \multirow[b]{3}{*}{$\begin{array}{c}\text { Nominal } \\
\text { Concentration } \\
\text { (conc), ng } / \mathrm{mL}\end{array}$} & \multicolumn{4}{|c|}{ Human } & \multicolumn{4}{|c|}{ Marmoset monkey } & \multicolumn{4}{|c|}{ Rat } & \multicolumn{4}{|c|}{ Mouse } \\
\hline & & \multicolumn{4}{|c|}{ Intra-assay (n=3) } & \multicolumn{4}{|c|}{ Intra-assay (n=3) } & \multicolumn{4}{|c|}{ Intra-assay ( $\mathrm{n}=3$ ) } & \multicolumn{4}{|c|}{ Intra-assay $(\mathrm{n}=3$ ) } \\
\hline & & \begin{tabular}{|c|}
$\begin{array}{c}\text { Calculated } \\
\text { conc., } \\
\text { (ng/mL) }\end{array}$ \\
\end{tabular} & $\begin{array}{c}\begin{array}{c}\text { Standard } \\
\text { deviation } \\
(\mathrm{ng} / \mathrm{mL})\end{array} \\
\end{array}$ & $\begin{array}{c}\text { Accuracy } \\
(\%)\end{array}$ & $\begin{array}{c}\text { Precision } \\
\text { (\%) }\end{array}$ & \begin{tabular}{|c|}
$\begin{array}{c}\text { Calculated } \\
\text { conc., } \\
(\mathrm{ng} / \mathrm{mL})\end{array}$ \\
\end{tabular} & $\begin{array}{l}\text { Standard } \\
\text { deviation } \\
(\mathrm{ng} / \mathrm{mL})\end{array}$ & $\begin{array}{c}\text { Accuracy } \\
(\%)\end{array}$ & $\begin{array}{c}\text { Precision } \\
(\%)\end{array}$ & $\begin{array}{c}\begin{array}{c}\text { Calculated } \\
\text { conc., } \\
\text { (ng/mL) }\end{array} \\
\end{array}$ & $\begin{array}{l}\text { Standard } \\
\text { deviation } \\
(\mathrm{ng} / \mathrm{mL})\end{array}$ & $\begin{array}{c}\text { Accuracy } \\
(\%)\end{array}$ & $\begin{array}{c}\text { Precision } \\
(\%)\end{array}$ & $\begin{array}{c}\begin{array}{c}\text { Calculated } \\
\text { conc., } \\
\text { (ng/mL) }\end{array} \\
\end{array}$ & $\begin{array}{c}\text { Standard } \\
\text { deviation } \\
(\mathrm{ng} / \mathrm{mL})\end{array}$ & $\begin{array}{c}\text { Accuracy } \\
(\%)\end{array}$ & $\begin{array}{c}\text { Precision } \\
(\%)\end{array}$ \\
\hline \multirow{3}{*}{ S-bupropion } & 0.1 & 0.1 & 0.02 & 80 & 20 & 0.1 & 0.02 & 113 & 14 & 0.1 & 0.003 & 117 & 3 & 0.1 & 0.01 & 111 & 9 \\
\hline & 1 & 0.9 & 0.06 & 93 & 7 & 0.9 & 0.1 & 91 & 11 & 1.2 & 0.03 & 116 & 3 & 0.9 & 0.08 & 90 & 9 \\
\hline & 10 & 8.7 & 1.58 & 87 & 18 & 9.9 & 0.89 & 99 & 9 & 10.3 & 1.77 & 103 & 17 & 10.6 & 0.96 & 106 & 9 \\
\hline \multirow{3}{*}{ S,S-hydroxybupropion } & 0.1 & 0.1 & 0.02 & 110 & 14 & 0.1 & 0.01 & 108 & 10 & 0.1 & 0.001 & 83 & 2 & 0.1 & 0.02 & 93 & 19 \\
\hline & 1 & 0.9 & 0.02 & 86 & 2 & 1.0 & 0.06 & 103 & 6 & 1 & 0.03 & 105 & 2 & 0.9 & 0.03 & 90 & 3 \\
\hline & 10 & 9.4 & 1.41 & 94 & 15 & 11.1 & 0.69 & 111 & 6 & 10.6 & 0.6 & 106 & 6 & 9.8 & 1.31 & 98 & 13 \\
\hline \multirow{3}{*}{ R,S-erythrohydrobupropion } & 0.1 & 0.1 & 0.02 & 95 & 13 & 0.1 & 0.01 & 90 & 6 & 0.1 & 0.003 & 108 & 3 & 0.1 & 0.01 & 91 & 11 \\
\hline & 1 & 1.1 & 0.01 & 111 & 0 & 1.1 & 0.09 & 112 & 8 & 1.0 & 0.13 & 104 & 12 & 1.1 & 0.03 & 107 & 2 \\
\hline & 10 & 10.4 & 0.78 & 104 & 7 & 11.2 & 0.39 & 112 & 3 & 9.1 & 0.36 & 91 & 4 & 11.0 & 0.61 & 110 & 6 \\
\hline \multirow{3}{*}{ S,S-threohydrobupropion } & 0.1 & 0.1 & 0.01 & 100 & 11 & 0.1 & 0.01 & 116 & 9 & 0.1 & 0.004 & 114 & 3 & 0.1 & 0.002 & 92 & 2 \\
\hline & 1 & 1.2 & 0.04 & 117 & 3 & 1.2 & 0.03 & 115 & 2 & 0.8 & 0.02 & 83 & 3 & 1.1 & 0.11 & 111 & 10 \\
\hline & 10 & 10.9 & 1.11 & 109 & 10 & 11.3 & 1.19 & 113 & 11 & 8.7 & 0.75 & 87 & 9 & 10.8 & 0.89 & 108 & 8 \\
\hline \multirow{3}{*}{ R-bupropion } & 1 & 1.1 & 0.17 & 111 & 16 & 1.0 & 0.05 & 99 & 6 & 0.9 & 0.02 & 85 & 2 & 1.2 & 0.0006 & 119 & 0 \\
\hline & 100 & 94.6 & 12.55 & 95 & 13 & 108.9 & 11.91 & 109 & 11 & 99.2 & 6.19 & 99 & 6 & 106.3 & 12.56 & 106 & 12 \\
\hline & 500 & 538.4 & 81.85 & 108 & 15 & 518.7 & 73.39 & 104 & 14 & 524.5 & 84.25 & 105 & 16 & 522.4 & 19.02 & 104 & 4 \\
\hline \multirow{3}{*}{ R,R-hydroxybupropion } & 1 & 1.2 & 0.01 & 119 & 1 & 1.1 & 0.24 & 114 & 2 & 1.1 & 0.06 & 111 & 6 & 1.2 & 0.04 & 119 & 2 \\
\hline & 100 & 114.0 & 3.86 & 114 & 3 & 119.2 & 0.62 & 119 & 1 & 101.8 & 15.36 & 102 & 15 & 116.1 & 5.18 & 116 & 4 \\
\hline & 500 & 497.5 & 77.28 & 100 & 16 & 504.3 & 75.85 & 101 & 15 & 549.5 & 62.36 & 110 & 11 & 527.2 & 60.27 & 105 & 11 \\
\hline \multirow{3}{*}{ S,R-erythrohydrobupropion } & 1 & 1.2 & 0.13 & 120 & 11 & 0.9 & 0.19 & 93 & 20 & 1.0 & 0.07 & 100 & 7 & 1.1 & 0.04 & 113 & 4 \\
\hline & 100 & 108.2 & 10.95 & 108 & 10 & 106.4 & 8.31 & 106 & 8 & 81.7 & 1.94 & 82 & 2 & 116.9 & 3.4 & 117 & 3 \\
\hline & 500 & 497.4 & 52.16 & 99 & 10 & 508.8 & 70.28 & 102 & 14 & 481.9 & 59.51 & 96 & 12 & 557.3 & 33.56 & 111 & 6 \\
\hline \multirow{3}{*}{$\mathrm{R}, \mathrm{R}$-threohydrobupropion } & 1 & 1.2 & 0.22 & 118 & 19 & 1.1 & 0.02 & 114 & 2 & 1.2 & 0.03 & 115 & 2 & 1.2 & 0.06 & 120 & 5 \\
\hline & 100 & 99.9 & 6.11 & 100 & 6 & 109.8 & 5.07 & 110 & 5 & 98.8 & 0.95 & 99 & 1 & 117.4 & 1.48 & 117 & 1 \\
\hline & 500 & 479.5 & 58.21 & 96 & 12 & 512.3 & 87.94 & 102 & 17 & 503.9 & 47.22 & 101 & 9 & 517.1 & 61.26 & 103 & 12 \\
\hline
\end{tabular}




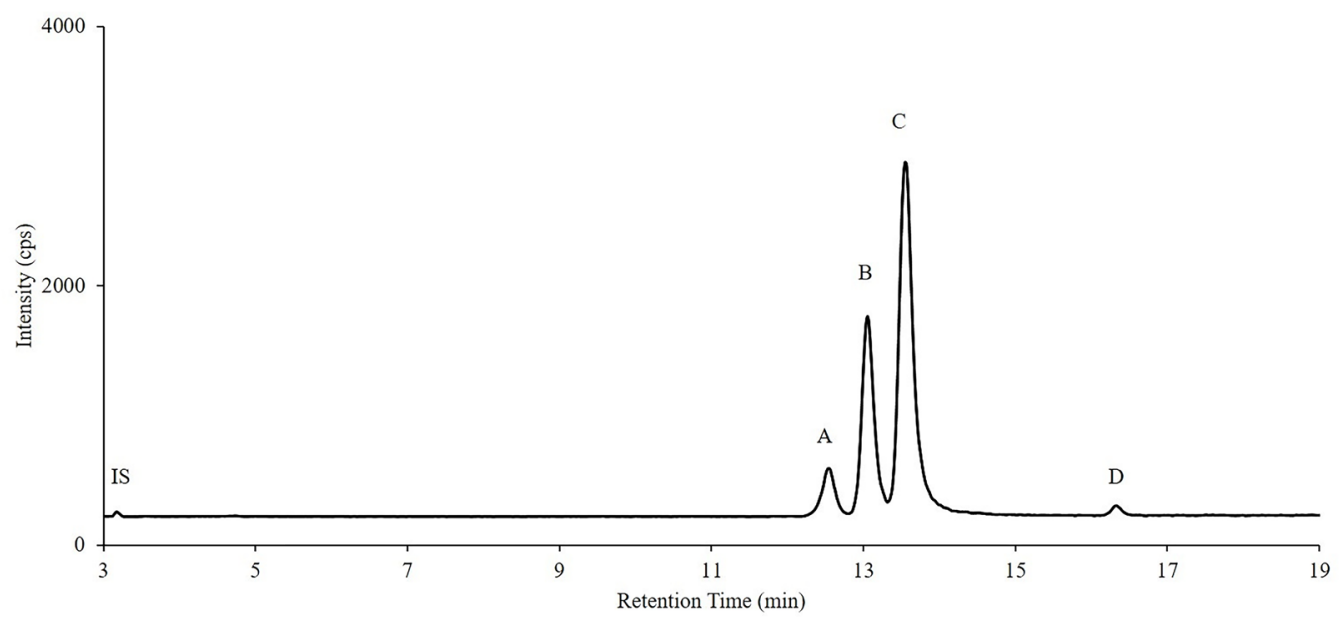

Supporting Information Figure 1 